\title{
Under-Water Superoleophobicity of Heat Treated and Chemically Etched Hypoeutectic Aluminum- 8 wt.\% Silicon Alloy
}

\section{Aniedi E Nyong ${ }^{1 *}$, Edet W Nsi', Joachim J Awaka-Ama', Aniefiok E Ite ${ }^{1}$, Emmanuel E Ubuo $^{1}$ and Pradeep K Rohatgi ${ }^{2}$}

${ }^{1}$ Department of Chemistry, Materials Chemistry Research Unit, Akwa-Ibom State University, Nigeria

${ }^{2}$ Department of Materials Science and Engineering, University of Wisconsin-Milwaukee, USA

\begin{abstract}
Hypoeutectic aluminum-silicon alloy consisting of 8.0 wt.\% silicon and prepared through a solid-phase technique was studied for the contact angle behaviour of oil in under-water condition. The surface structure of the Al-8 wt.\% Si hypoeutectic alloy was modified through a solutionizing heat treatment process at $650{ }^{\circ} \mathrm{C}$ for 6 hours, quenching in water and etching in Keller's reagent. The modified surface structure showed an increase with the etch time for sizes of the secondary arm-spacing (SAS), from $5.31 \pm 2.54 \mu \mathrm{m}$ to $6.16 \pm 2.35 \mu \mathrm{m}$ for 5 to 20 seconds of etching respectively. Equally, while the average surface roughness $\left(R_{a}\right)$ increased from 0.1 to 0.74 microns, the sizes of the secondary dendrites (SSD) reduced considerably with increase in the etch time. These alterations of the surface structure influenced the fractional surface area $\left(f_{\text {so }}\right)$ and the evaluated contact angles of oil drops at the solid-water interface. Therefore, a gradual increase in the contact angles of oil, to a maximum value of $159.96 \pm 0.64$, was noted for the Al-8 wt.\% Si alloys after the solutionizing heat treatment, quenching and etching process, confirming significant under-water superoleophobicity.
\end{abstract}

\section{Keywords}

Superoleophobicity, Heat treatment, Etching, Hypoeutectic Al-Si alloy

\section{Introduction}

Aluminum and its alloys have enormous applications in the automotive, electrical as well as in the aerospace industries [1,2]. Due to this, the surfaces of aluminum and its alloys are often exposed to reactive liquids and oils in various situations, which can induce surface tarnishing, corrosion and fouling thereby reducing their time-span of usefulness. To this end, there has been considerable interest recently in the development of under-water superoleophobic surfaces on aluminum and its alloys for various reasons some of which are for self-cleaning, anti-smudge, anti-fouling and anti-corrosion applications $[3,4]$.

For instance, under-water superoleophobic surfaces have been developed on aluminum surfaces through a combination of electrochemical etching and immersion in boiling water. The surfaces so de-

*Corresponding author: Aniedi E Nyong, Materials Chemistry Research Unit, Department of Chemistry, Akwa-Ibom State University, Uyo, Nigeria

Accepted: August 12, 2019; Published: August 14, 2019

Copyright: (C) 2019 Nyong AE, et al. This is an open-access article distributed under the terms of the Creative Commons Attribution License, which permits unrestricted use, distribution, and reproduction in any medium, provided the original author and source are credited. 
veloped exhibited excellent, long-term stability of wettability [5].

Under-water superoleophobicity has been generated on the metallic surfaces, through femtosecond laser micromachining [6]. The surfaces generated through this method contained coral-like microstructures with nanoparticles which showed sustained chemical stability when exposed to various oils and also while immersed in water with different $\mathrm{pH}$ values. The measured contact angles of the various oils on these surfaces were all above $150^{\circ}$. In the same vein, under-water superoleophobic surfaces have been created on the surfaces of Ti6Al4V through the process of electrochemical etching [7]. The prepared surfaces all exhibited good under-water superoleophobicity with oil contact angle for dichloromethane in water as high as $158.9^{\circ} \pm 1.7^{\circ}$ with a corresponding sliding angle is $6.4^{\circ} \pm 1.4^{\circ}$ [8]. The effect of etch time on the under-water oil contact angles were also established and linked to the hierarchical micro/nanoscale surface roughness on the alloy surfaces. For the aluminum-silicon alloys, the amount of silicon are usually standardized, in the range of 5 to $23 \mathrm{wt} . \%$, to the extent that the alloys are hypoeutectic, eutectic or hypereutectic depending on the amount of silicon [9]. It is also worth stating that numerous approaches have been used in the synthesis of this alloy such as the liquid phase techniques [10], liquid-solid phase techniques and solid-phase techniques [11-13].

In this paper, we explore a simple, new and effective method of the creating under-water superoleophobic surfaces on a hypoeutectic aluminum-silicon alloy at the solid-water interface through a regime of heat treatment, quenching in water regime and chemical etching. These alloys are useful in the manufacture of pumps and compressors that get fouled easily in oily work environments. Thus, generating under-water superoleophobicity on their surfaces will have usefulness in preventing surface fouling and enhancing the alloy's life-span.

\section{Materials and Method}

\section{Materials}

For the synthesis of the alloy, a pure aluminum base substrate was used with silicon ( $\geq 98.5$ wt.\% $\mathrm{Si}$ ) as an additive. The aluminum and silicon were both obtained from the Centre of Composite Research, University of Wisconsin in Milwaukee.

\section{Method}

The synthesis of the hypoeutectic Al-8 wt.\% Si alloy involved the heating of aluminum with pure silicon (8 wt.\%) in a graphite crucible (D $89 \mathrm{~mm}$, Depth $127 \mathrm{~mm}$ ) via an induction furnace to a temperature of above $900{ }^{\circ} \mathrm{C}$. The temperature of the process was monitored by means of a thermocouple placed in the melt intermittently. The molten aluminum and silicon substrates were stirred vigorously with an impeller for proper mix.

The alloy was allowed to cool in an inert atmosphere, created by argon gas and the ingots obtained thereof were weighed and then cut into smaller sizes for surface treatment through grinding and polishing, heat treatment and chemical etching with Keller solution.

The samples were grinded and polished using different grit-sizes of Silicon Carbide paper and finally with a soft cloth impregnated with $0.1 \mathrm{mi}-$ cron alumina slurry. These polished samples were washed in plenty of distilled water and in ethanol and then allowed to dry in air.

The structural alteration of the surfaces of the samples involved the heat treatment of the alloy for 6 hours at $650^{\circ} \mathrm{C}$ in an electric furnace (Thermolyne model from Thermo-scientific) and quenching in water, followed by etching of the samples to varied degrees of time. The Keller's solution was used for the chemical etching of the Al-Si alloy samples consisted of Nitric acid $(5 \mathrm{ml})$, Hydrochloric acid $(3 \mathrm{ml})$, and Hydrofluoric acid $(2 \mathrm{ml})$ mixed in distilled water $(190 \mathrm{ml})$. The etched samples were equally washed in distilled water and allowed to dry again in air.

The characterization of the sample surfaces involved surface structure examinations using the scanning electron microscope - the Hitachi-S4800 model, surface roughness measurements using the 2-D surface roughness profilometer - phase II SGR4500 model and contact angle of oil measurements at the solid-liquid interface using the contact angle goniometer- Rame Hart 250 model.

The SEM examinations of the surface structures were done at both high and low magnifications. The scanning electron microscope had an attached energy dispersive $\mathrm{x}$-ray probe that was used for further chemical examination of the surfaces and quantitative assessment of the amount of silicon in the synthesized alloy under a high vacuum of $15.0 \mathrm{KV}$. The measurement of the average surface 
roughness involved five measurements at different spots on the surfaces from which the average was calculated.

Similarly, the contact angles were measured by putting drops of oil of about $5 \mu$ on the surfaces of samples that are immersed in water, with the aid of a micro-syringe. This is illustrated in Figure 1.

The oil drop images were captured with the goniometer using the dropimage software, from which the contact angles were measured. This was repeated for five times and the average values of

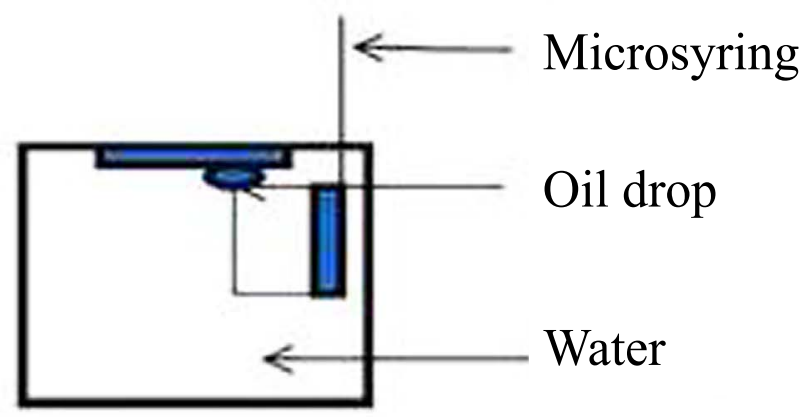

Figure 1: Experimental set up for the measurement of the oil drop contact angle under water. the contact angles of the oil drops calculated.

\section{Results and Discussion}

The results obtained from the various experiments, based on the above method are stated and discussed as follows:

\section{SEM evaluation of the surfaces}

Aluminum-Silicon alloys are polyphased materials consisting of $\alpha$-aluminum solid solution and silicon [14]. The SEM micrographs of the surfaces, presented in Figure 2 and Figure 3, showed that it consisted of a network of dendrites, spread across the surfaces in various directions and particulates of solidified silicon. Due to the heat treatment and quenching in cold water applied to the samples, the dendrites formed were more pronounced, with well-defined secondary dendritic arms (SAS). The quenching ensured that the aluminum-silicon solid solution cooled rapidly to room temperature thereby preventing the diffusion of the elements and ensuring that the morphology of the surface structure is effectively frozen inside the alloy. The silicon particles, in the form of coarse, plate-like particulates
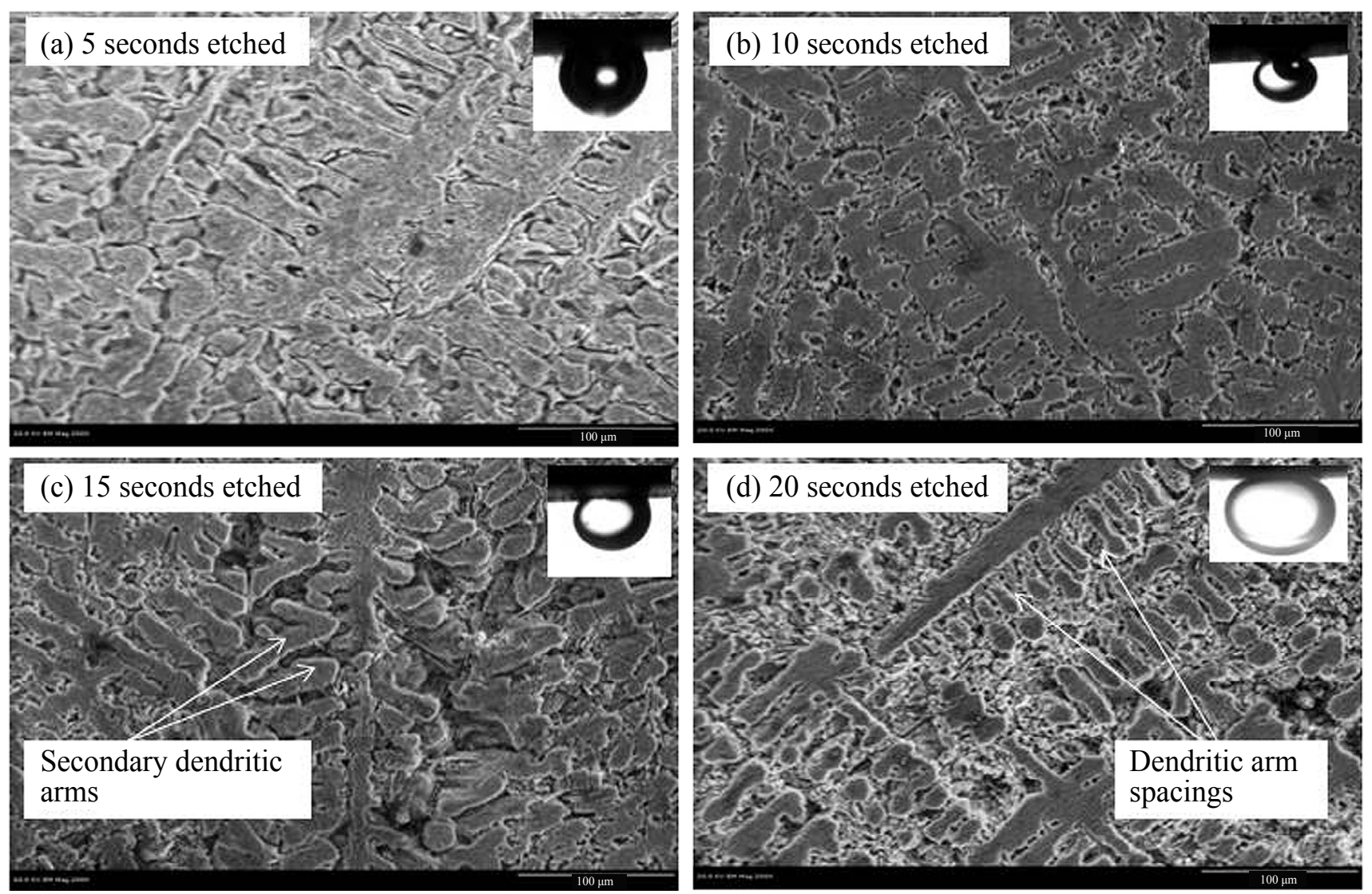

Figure 2: Microstructure of Al-8 wt.\% Si alloy ater etching: a) 5 seconds; b) 10 seconds; c) 15 seconds; d) 20 seconds in Keller's solution. 


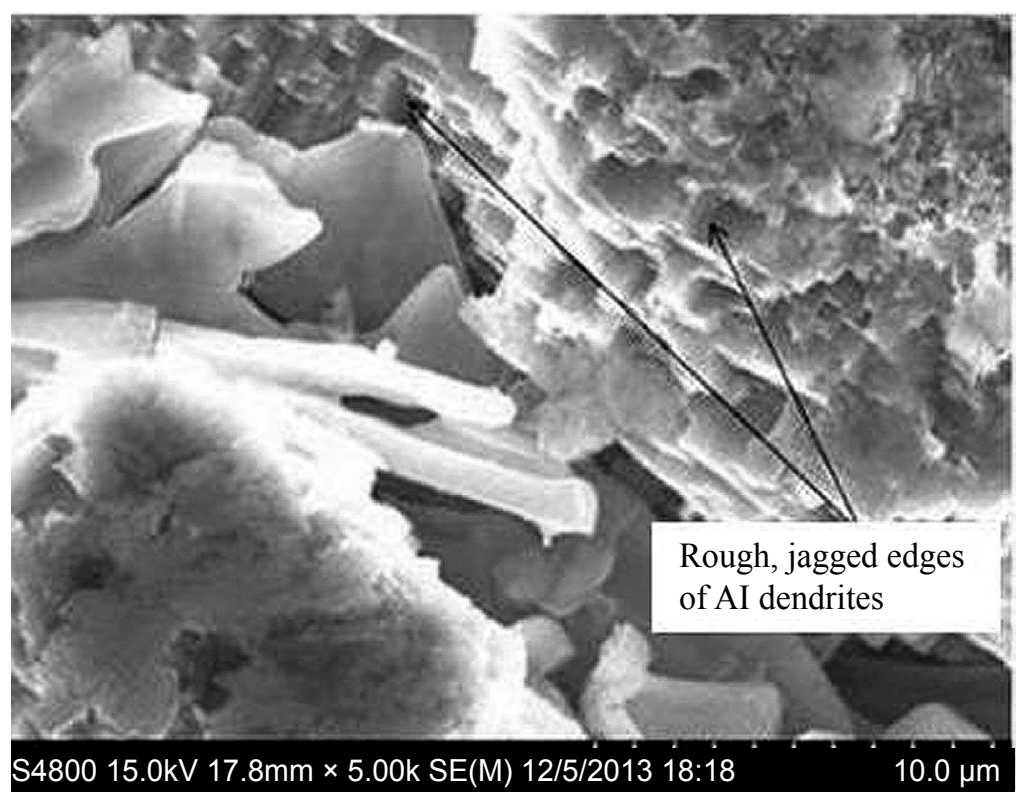

Figure 3: Higher magnification image of the microstructure of the Al- 8 wt.\% Si alloy showing the jagged dendritic features.
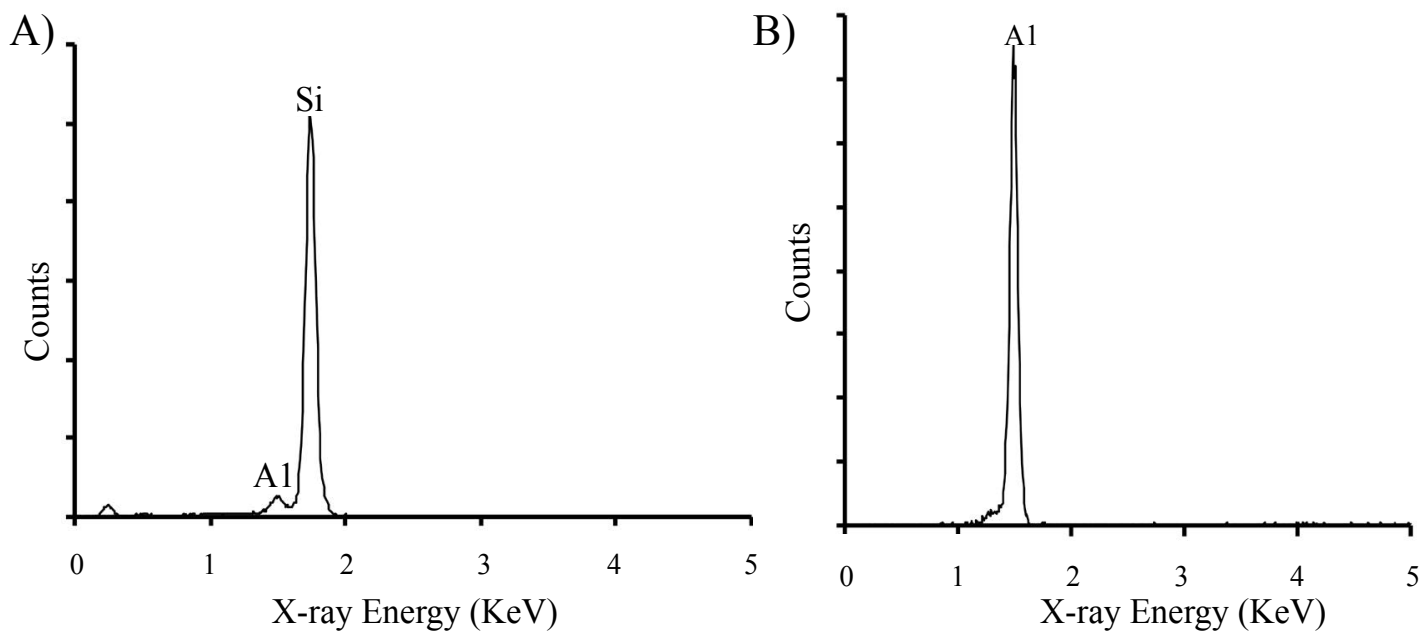

Figure 4: EDX of the surface structure of Al-8 wt.\% Si alloy: a) Si particle; b) $\alpha$-Al dendrite.

[15] were found within the spacings between the secondary dendritic arms. The average sizes of the secondary arm spacings (SAS) for these network of surface dendrites were $5.31 \pm 2.54 \mu \mathrm{m}, 5.40 \pm$ $1.30 \mu \mathrm{m}, 5.53 \pm 1.76 \mu \mathrm{m}$ and $6.16 \pm 2.35 \mu \mathrm{m}$ for the samples etched for $5,10,15$ and 20 seconds respectively. This showed that the secondary arm spacings (SAS) increased with increase in the etch time. The etch time here refers to the period of exposure of the samples, through immersion, to the etching solution.

An energy dispersive $\mathrm{x}$-ray analyses (EDX spot analyses), presented in Figure $4 a$ and Figure $4 b$, confirmed that the dendrites consisted of alumi- num. Equally, the EDX spot analyses showed that the inter-dendritic and secondary arms spacing consisted of silicon, implying that the eutectic silicon phase in the form of the silicon particulates of various sizes, were formed within these spaces.

Some residual aluminum was however noticed in the interfacial region between the aluminum and silicon phases. This is ascribed to the differences in the rates of solidification of the aluminum and silicon phases from the molten melt [16]. The phases confirmed from the EDX analyses are in conformity with the phases predicted from the binary aluminum-silicon phase diagram [17]. The two phases exhibited divorced morphology essen- 
tially due to the high interfacial energies existing between both [18]. Chemical etching can be considered as a process resulting from electrolytic interaction between the $\alpha$-aluminum, the silicon phases and the chemical etchant [19]. The Keller's solution is therefore expected to show different levels of chemical activity on different areas of the alloy surfaces due to factors such as stress concentration within the surface structure and the difference in the potentials, in the form ionization of the $\alpha$-phase aluminum and eutectic silicon phases. To this end, those areas in the surface structures with stress concentrations, such as the edges of dendrites, showed higher chemical reactivity with the Keller's solution as noted by the roughened edges of the dendrites, as seen in the SEM image in Figure 3 .

From the ionization potential of the elemental components of the alloy, the relative ease in which these $\alpha$ - aluminum and silicon phases can engage in chemical reactions can be appraised using their respective ionization energies [20].

The fourth ionization energy of silicon is very high (4356 KJ mol-1) compared to the third ionization energy of aluminum (2745 $\left.\mathrm{KJ} \mathrm{mol}^{-1}\right)$ [21]. Therefore, the formation of $\mathrm{Al}^{3+}$ ions through the process of oxidation is expected to be less energetic and therefore more favorable compared to the formation of $\mathrm{Si}^{4+}$ from the silicon phase. Thus, it is expected that the $\alpha$-aluminum phase of the alloy will be more easily tarnished chemically, in the presence of the etchant when compared to silicon particles due to the higher ionization potential of the later.

Some of the expected reactions as a result of the chemical etching of the samples with the Keller's solution are stated in these series of equations [22]: (i) $3 \mathrm{HNO}_{3}+\mathrm{Al} \rightarrow 1.5 \mathrm{H}_{2}+\mathrm{Al}\left(\mathrm{NO}_{3}\right)_{3}$

(ii) $3 \mathrm{HF}+\mathrm{Al} \rightarrow 1.5 \mathrm{H}_{2}+\mathrm{AlF}_{3}$

(iii) $3 \mathrm{Si}+18 \mathrm{HF}+4 \mathrm{HNO}_{3} \rightarrow 3 \mathrm{H}_{2} \mathrm{SiF}_{6}+4 \mathrm{NO}+8 \mathrm{H}_{2} \mathrm{O}$

Some other reactions may have occurred but these have not be established in literature or investigated herein. Following the etching process, the dendritic structures representing the $\alpha$-aluminum phase exhibited quite jagged and rough edges in comparison to the silicon particles.

\section{Variation of surface roughness and the sizes of the secondary dendritic arms with the etch time}

This rough, jagged edges of the dendrites within the surface structures and the eutectic silicon particles present therein induced an increase in the average roughness $R_{a}$ values of the samples after the heat treatment, quenching and chemical etching processes.

The values of $R_{a}$ are presented in Table 1. Beyond the increase in the surface average roughness, the sizes of the secondary dendrites decreased with increase in etching time. This reduction in the sizes of the secondary dendritic arms is simply because of the preferential corroding chemical action of the Keller's reagent.

\section{Behaviour of contact angle of oil at the solid- water interface on chemical etching}

The contact angles of oil, $\Theta_{\text {oil }}$ at the solid-water interface are stated in Table 1 . It can be seen that there was a gradual increase in the $\Theta_{\text {oil }}$ as the etch time for the heat treated samples increased. This variation of $\theta_{\text {oil }}$ with the etch time is shown graphically with the plot presented in Figure 5.

The maximum value of $159.96 \pm 0.64^{\circ}$ was noted when the samples exposed to the heat treatment/ quenching in cold water regime, were etched for

Table 1: Table showing the variation of the average surface roughness $\left(R_{a}\right)$, Secondary arm spacing (SAS), size of secondary dendrites, $\mathrm{f}_{\text {so }}$ and contact angle of oil $\left(\Theta_{\text {oil }}\right)$ at the solid-water interface.

\begin{tabular}{|l|l|l|l|l|l|l|}
\hline $\begin{array}{l}\text { Etching time } \\
\text { (seconds) }\end{array}$ & $\mathbf{R}_{\mathbf{a}}$ & SAS & $\begin{array}{l}\text { Size of secondary } \\
\text { dendrite }\end{array}$ & $\begin{array}{l}\mathbf{f}_{\text {so }} \text { (from } \\
\text { eqn. 1) }\end{array}$ & $\begin{array}{l}\mathbf{f}_{\text {so }} \text { (from } \\
\text { eqn. 2) }\end{array}$ & $\boldsymbol{\Theta}_{\text {oil }}$ \\
\hline 0 & 0.1 & - & & - & & $54 \pm 2^{\circ}$ \\
\hline 5 & 0.35 & $5.31 \pm 1.54$ & $14.14 \pm 3.16$ & 0.57 & 0.89 & $103.28 \pm 1.32^{\circ}$ \\
\hline 10 & 0.42 & $5.40 \pm 1.30$ & $12.39 \pm 2.67$ & 0.53 & 0.68 & $114.44 \pm 6.02^{\circ}$ \\
\hline 15 & 0.61 & $5.53 \pm 1.76$ & $12.32 \pm 1.12$ & 0.52 & 0.41 & $130.61 \pm 0.99^{\circ}$ \\
\hline 20 & 0.74 & $6.16 \pm 2.35$ & $11.61 \pm 2.88$ & 0.48 & 0.08 & $159.96 \pm 0.64^{\circ}$ \\
\hline
\end{tabular}




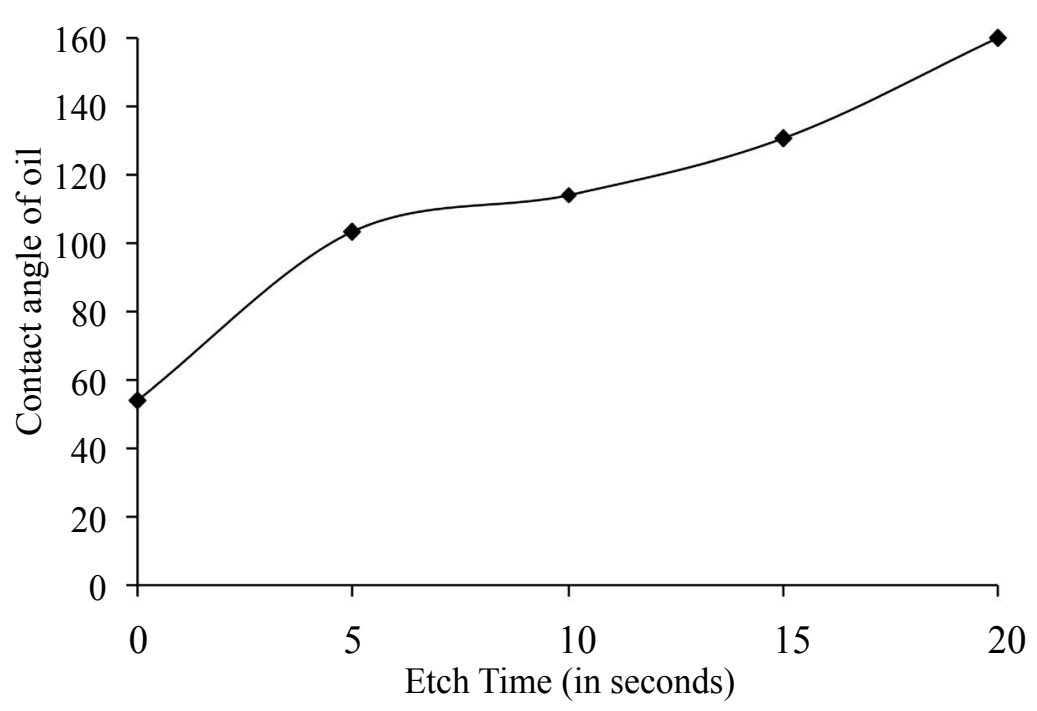

Figure 5: Plot of the variation of the under-water contact angle of oil against etching time.

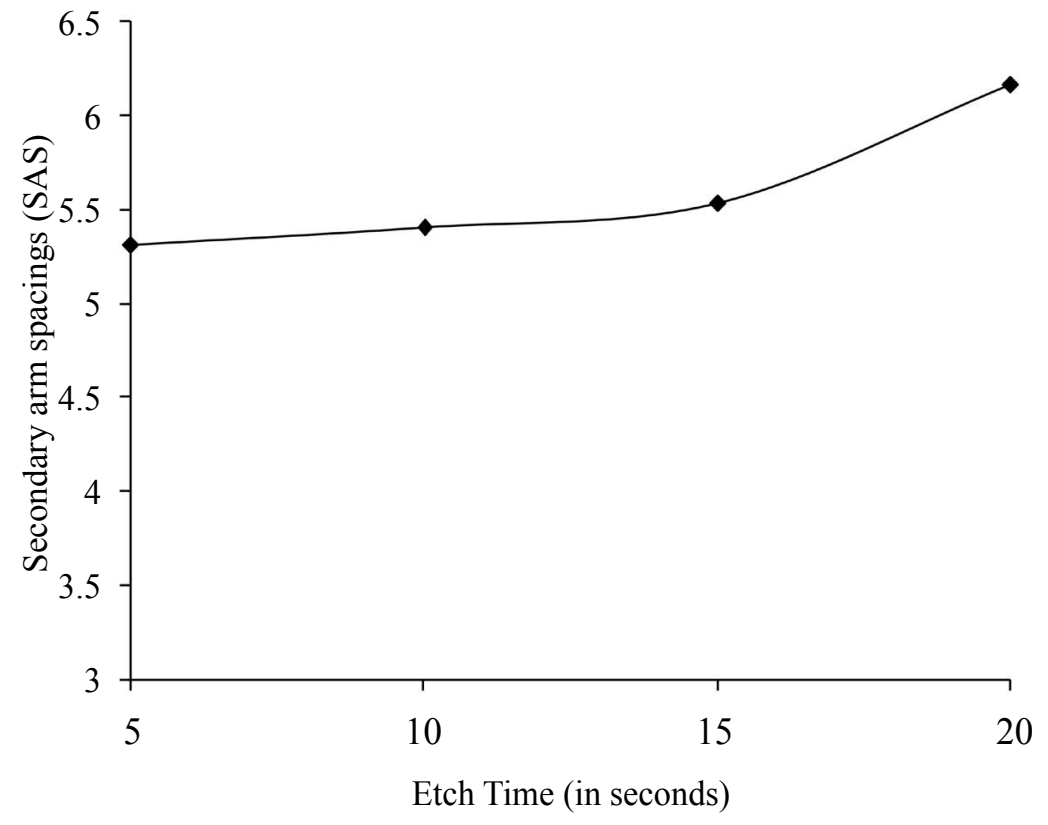

Figure 6: Plot of the variation of the secondary arm spacing withe the chemical etching time.

20 seconds. This increase in the oil contact angles is due to two factors, namely the increase in the average roughness of the surface, $R_{a}$ and the reduction in the fractional surface area, $f_{s^{\prime}}$, available for the wetting. The heat treatment and quenching process produced well defined network of dendrites on the surfaces and the etching of this dendritic network caused an increase in the average surface roughness, $R_{a}$, of the surfaces. This contributed to the gradual increase in the oil contact angle witnessed at the solid-water interface. Beyond the effect of increasing the surface roughness, the degradation of the dendrites resulted in the alteration of the sizes of the secondary arms and the spacings between them. These changes in these surface features affected the fractional surface area available for wetting by the oil drops, $f_{\text {so }}$. This increase in the secondary arm spacings of the dendrites observed in the surface structures is shown in the graph in Figure 6.

A conceptualisation of the surface dendritic network, based on Figure 7, can be used to calculate the $f_{\text {so }}$ by using the relationship stated in equation 1 :

$$
\mathrm{f}_{\text {so }}=\frac{\mathrm{SSA}}{2 \mathrm{SAS}+\mathrm{SSA}}
$$




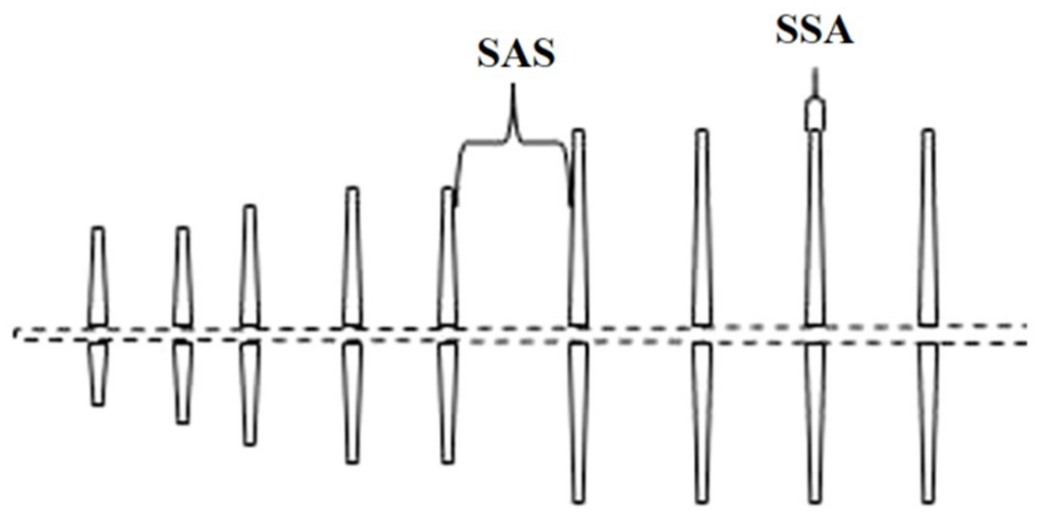

Figure 7: Illustration of the dendritic structure for the estimation of $f_{\text {so }} .(S A S=$ Secondary arm spacing, SSA = Size of secondary arm).

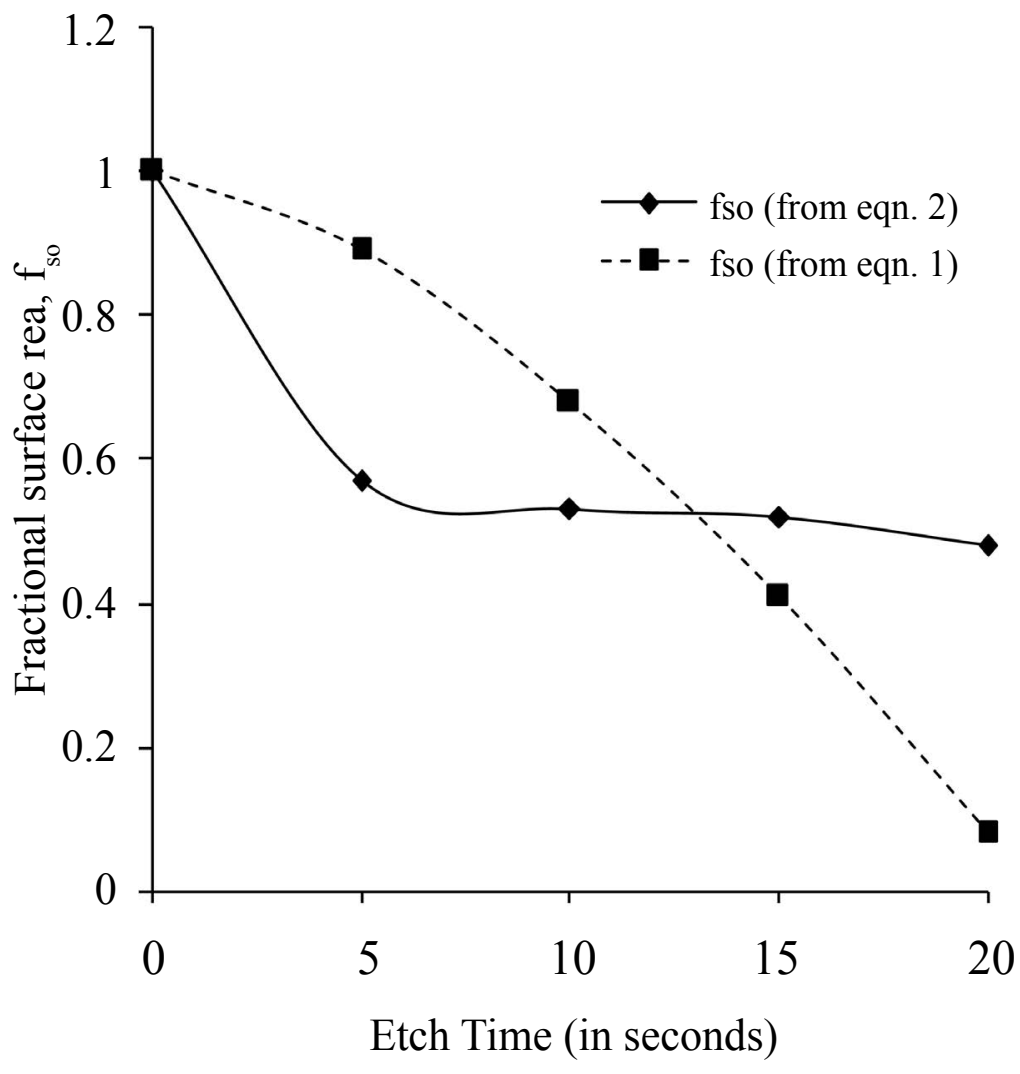

Figure 8: Plot of the variation of the fractional surface area $f_{\text {so }}$ with etching time.

The values of $f_{\text {so }}$ were calculated from SAS and SSA estimated directly from the SEM images of the surface structures, as seen in the average values of twenty (20) such measurements for both presented in Table 1. The estimated values of $f_{\text {so }}$ decreased with increase in the etching time. The values of the $f_{\text {so }}$ were also evaluated using the Cassie-Baxter model [23-25], given by equation 2 , with $\theta$ equal to the underwater oil contact angle on the polished, untreated Al-8 wt.\% Si hypoeutectic alloy $(\theta=54$ $\pm 2^{\circ}$ ) and $\theta_{\circ}$ equal to the measured underwater oil contact angle values on the heat treated and chemically etched samples of the alloy.

$$
\cos \theta_{\mathrm{o}}=f_{\mathrm{so}}(\cos \theta+1)-1
$$

The plot of the fractional surface areas $f_{\text {so }}$ from equations 1 and 2, as presented in Figure 8, showed a gradual reduction in values with increase in the etching time.

The reduction in the values of $f_{s o}$ obtained from 
equation 1 were not as pronouced as that obtained from equation 2 . We attribute this difference in the values of $f_{s o}$ to the fact that it may not be only the differences in the sizes of the secondary dendritic arms and the spacings between them that have affected the fractional surfaces available for wetting by the oil drops. Therefore, the disruptions of the dendrite surfaces due to the chemical etching as well as the presence of silicon eutectic particles must equally have contributed to the reduction in $f_{s o}$.

In summary, the mechanism for the underwater superoleophobicity on the surface of this alloy is attributed to this consistent reduction in the fractional surface area for wetting by the oil drops. The implication is that as the $f_{\text {so }}$ reduces, the under-water oil contact angles increases as the water molecules will be much and more easily trapped in the hierarchical micro/nanoscale structure generated by the etching of the heat-treated surfaces. The trapped water resist the penetration of the oil causing the under-water superoleophobicity noted.

\section{Conclusion}

In conclusion, though the high surface energy nature of the Al- 8 wt.\% Si alloys conveys on it a certain level of oleophobicity, the processes of heat treatment and quenching and chemical etching of the hypoeutectic Al-8 wt.\% Si alloy samples sufficiently modified the surface structure of the alloy to the extent of sustaining under-water superoleophobicity with a high contact angle of oil of $159.96^{\circ}$ $\pm 0.64^{\circ}$. This high under-water oil contact angle is ascribed to optimal fractional surface area and increase in the surface roughness caused by the heat-treatment, quenching, and etching processes.

\section{References}

1. Alam T, Ansari AH (2017) Review on aluminium and its alloys for automotive applications. International Journal of Advanced Technology in Engineering and Science 5: 278-294.

2. Gandara M (2013) Aluminum: The metal of choice. Materials and Technology 47: 261-265.

3. Varsgney P, Mohaptra S, Kumar A (2007) Fabrication of mechanically stable superhydrophobic aluminum surface with excellent self-cleaning and anti-fogging properties. Biomimetics 2: 1-12.

4. Peng S, Bhushan B (2016) Mechanically stable superoleophobic aluminum surfaces with microstep and nanoreticula hierarchical structure for self-cleaning and anti-smudge properties. J Colloid Interface Sci 461: 273-284.

5. Wang LL, Sun YW, Goa YZ, Guo DM (2016) Preparation of durable underwater superoleophobic Ti6Al4V surfaces by electrochemical etching. Surface Engineering 32: 85-94.

6. Yin K, Song YX, Dong XR, Wang C, Duan JA (2016) Underwater superoleophobicity, anti-oil and ultrabroadband enhanced absorption of metallic surfaces produced by a femtosecond laser inspired by fish and chameleons. Sci Rep 6: 1-8.

7. Ma Ning, Chen Y, Zhao S, Li J, Shan B, et al. (2018) Preparation of superhydrophobic and superoleophobic Al-Mg alloy surface via simple, environmentally friendly method. Journal of Material Research 33: 1-9.

8. Ji S, Ramadhianti P, Nguyen T, Kim W, Lim H (2013) Simple fabrication approach for superhydrophobic and superoleophobic Al surface. Microelectronic Engineering 111: 404-408.

9. Jiang X, Han Q (2013) Formation of hypoeutectic silicon particles in hypoeutectic Al-Si alloys under the influence of high -intensity ultrasonic vibration. China Foundry 10: 118-122.

10.Caceres CH, Selling BI (1996) Casting defects and the tensile properties of an AlSiMg alloy. Materials Science and Engineering A 220: 109-116.

11.Valer Goni J, Rodrguez-Ibabe JM, Urcola JJ (1997) Influence of microstructure on mechanical properties of hypereutectic Al-Si alloys. Key Engineering Materials 127: 911-918.

12.Anand S, Srivastsan TS, Wu Y, Lavernia EJ (1997) Processing, microstructure and fracture behaviour of a spray atomized and deposited aluminum-silicon alloy. Journal of Materials Science 32: 2835-2848.

13.ZhouJ, DuszczykJ, Korevaar BM (1991)Microstructural features and final mechanical properties of the ironmodified Al-20Si-3Cu-1 Mg alloy product processed from atomized powder. Journal of Materials Science 26: 3041-3050.

14.Davis JR (1993) ASM specialty handbook: Aluminum and aluminum alloys. ASM International, United State.

15.Lu SZ, Hellawell A (1995) Modification of aluminumsilicon alloys: Microstructure, thermal analysis and mechanisms. JOM 47: 38-40.

16.Kim KY (2014) Separation of primary solid phases from Al-Si alloy melts. China Foundry 11: 382-395. 
17.Vander Voort GF, Asencio-Lozano JT (2009) The Al-Si Phase diagram. Microsc Microanal 15: 60-61.

18.Gupta M, Lavernia EJ (1995) Effect of processing on the microstructural variation and heat-treatment response of a hypereutectic Al-Si alloy. Journal of Materials Processing Technology 54: 261-270.

19. Qian B, Shen Z (2005) Fabrication of superhydrophobic surfaces by dislocation-selective chemical etching on aluminum, copper, and zinc substrates. Langmuir 21: 9007-9009.

20.Osório WR, Goulart PR, Garcia A (2008) Effect of silicon content on microstructure and electrochemical behavior of hypoeutectic Al-Si alloys. Materials Letters 62: 365-369.

21.CE Housecroft, AG Sharpe (2008) Inorganic Chemistry. ( $4^{\text {th }}$ edn), Pearson Education Limited, England.
22.Takami K, Kobashi M, Shiraga $Y$, Uddin $M$, Kato $Y$, et al. (2015) Effect of $\mathrm{HF}$ and $\mathrm{HNO}_{3}$ concentration on etching rate of each component in waste crystalline silicon solar cells. Materials Transaction 56: 20472052.

23. Cassie ABD, Baxter S (1944) Wettability of porous surfaces. Transaction of the Faraday Society 40: 546551.

24.Seo K, Kim M, Kim DH (2015) Re-derivation of Young's Equation, Wenzel Equation, and Cassie-Baxter Equation based on energy minimization. Surface Energy.

25.Z Yongmei, C Qunfeng, H Yongping, Y Chen (2016) Bio-Inspired wettability surfaces: Developments in micro- and nanostructures. CRS Press, Taylor and Francis Group, 1-4. 